\title{
Assessing Mechanical Properties of Natural Fibre Reinforced Composites for Engineering Applications
}

\author{
Olusegun David Samuel ${ }^{1 *}$, Stephen Agbo $^{2}$, Timothy Adesoye Adekanye ${ }^{3}$ \\ ${ }^{1}$ Department of Mechanical Engineering, Olabisi Onabanjo University, Ago-Iwoye, Nigeria \\ ${ }^{2}$ Department of Mechanical Engineering, Lagos City Polytechnic, Ikeja, Nigeria \\ ${ }^{3}$ Department of Agricultural Engineering, Landmark University, Omuaran, Nigeria \\ Email: *samolud@yahoo.com, steveagbo1@yahoo.com
}

Received March 4, 2012; revised April 20, 2012; accepted May 15, 2012

\begin{abstract}
Mechanical properties of ukam, banana, sisal, coconut, hemp and E-glass fibre reinforced laminates were evaluated to assess the possibility of using it as new material in engineering applications. Samples were fabricated by the hand lay-up process (30:70 fibre and matrix ratio by weight) and the properties evaluated using the INSTRON material testing system. The mechanical properties were tested and showed that glass laminate has the maximum tensile strength of $63 \mathrm{MPa}$, bending strength of $0.5 \mathrm{MPa}$, compressive strength of $37.75 \mathrm{MPa}$ and the impact strength of $17.82 \mathrm{~J} / \mathrm{m}^{2}$. The ukam plant fibre laminate has the maximum tensile strength of $16.25 \mathrm{MPa}$ and the impact strength of $9.8 \mathrm{~J} / \mathrm{m}$ among the natural fibres; the sisal laminate has the maximum compressive strength of $42 \mathrm{MPa}$ and maximum bending strength of $0.0036 \mathrm{MPa}$ among the natural fibres. Results indicated that natural fibres are of interest for low-cost engineering applications and can compete with artificial glass fibres (E-glass fibre) when a high stiffness per unit weight is desirable. Results also indicated that future research towards significant improvements in tensile and impact strength of these types of composites should focus on the optimisation of fibre strength rather than interfacial bond strength.
\end{abstract}

Keywords: Reinforced Laminates; Hand Lay-Up Method; E-Glass Fibre Reinforced; Natural Fibre

\section{Introduction}

Research and development of natural fibres as reinforcement for automotive sectors is a growing interest to scientists and engineers. Nowadays, natural fibres form is an interesting option for the most widely applied fibre in the composite technology. Many studies on natural studies such as keraf, bagasse, jute, ramie, hemp and oil palm [1-9]. Fibre reinforced composites with thermoplastic matrices have successfully proven their high qualities in various fields of engineering application. However, Natural fibres generally have poor mechanical properties compared with synthetic fibres but these composites were used as a source of energy to make shelters, clothes, construction of weapons [10]. High cost of synthetic fibres and health hazards of abestors fibres have really necessitated the exploration of natural fibres [11]. Consequently, natural fibres have always formed wide applications from the time they gained commercial recognition. They possess desirable properties such as biodegrability, renewability, combustibility, lower durability, excellent mechanical properties, low density and low price. Stamboulis and Baley [12] reported that this excel-

${ }^{*}$ Corresponding author. lent price-performance ratio at low weight in combination with the environmentally friendly character is very important for the acceptance of natural fibres in large volume engineering markets, such as the automotive and construction industries.

Since the beginning of human existence, people have developed plant fiber composites. Brahmakumar et al. [13] reported that these composites were used as a source of energy to make shelters, clothes, construction of weapons. The use of fibres as cloth was centered largely in the country side, with higher quality textiles being available in the towns. In late medieval Germany and Italy, fibres were employed in cooked dishes, as fillers in pies and boiled soup.

A composite may be defined as a physical mixture of two or more different materials. The mixture has properties which are generally better than those of any one of the materials. It is necessary to use combinations of materials to solve problems because any one material alone cannot do so at an acceptable cost or performance. These composites were produced in simple shapes and easy design structures by positioning the structural elements on top of each other to create the desired design.

Strength of glass fibre reinforced composites depends 
not only on the properties of the components but also on the mechanism of composite failure which is a function of how well the composite was formed [14].

Oladele et al. [15] reported that the fibre/matrix has an important role in the micromechanical behaviour of composite. Lack of good adhesion with the polymeric matrix, and large moisture absorption of natural fibres adversely affect adhesion with hydrophobic matrix material .These problems often lead to premature ageing by degrading and loss of strength.

Natural fibre-reinforced composites have been increasingly utilized in quite widespread applications. Natural fibres are obtained from different parts of the plants, to name a few, for example jute, flax, kenaf, coconut, hemp, ukam, sisal, banana, pineapple fibres from the leaf; cotton and kapok from seed; coir and coconut from the fruit. For example hemp, jute, flax and sisal fibres are already used in automotive industry [16].

In polymeric composite terms, natural fibre reinforcement is a manufactured assembly of long or short bundles of natural fibres to produce a flat sheet or mat of one or more layers of fibres. These layers are held together either by mechanical interlocking of the fibres themselves or with a binder to hold these materials together giving the assembly sufficient integrity to be handled. The un-reinforced plastics have low density, are relatively easy to process, resistant to weathering and do not require a surface finish.

The components of natural fibres are cellulose, hemicellulose, lignin, pectin, waxes and water soluble substances. The cellulose, hemicellulose and lignin are the basic components of natural fibres, governing the physical properties of the fibres [17]. In order to fully utilize the natural fibres, understanding their physical and mechanical properties is vital. A unique characteristic of natural fibres is depended upon the variations in the characteristics and amount of these components, as well as difference in its cellular structure. Therefore, to use natural fibres to its best advantages and most effectively in automotive and industrial application, physical and mechanical properties of natural fibres must be considered. Many studies have investigated the properties of natural fibres. Numerous researchers have studied mechanical properties of varied natural fibres [18]. Traditionally, natural fibres are used and known for rope, twine, and course sacking materials; and they are biodegradable and environmentally friendly crop. All mentioned studies have assisted engineers with the design and efficient usage of the natural fibres. However, the fibers modification is required and needed to improve mechanical properties for composites product. Efficiency of the fiber-reinforced composites also depends on the manufacturing process that the ability to transfer stress from the matrix to fiber [19]. In this study, natural fibre laminated laminates were made by hand lay-up method and their mechanical properties were investigated in order to assess its suitability.

\section{Material and Methods}

\subsection{Materials and Equipment}

The composite materials used in the production of the specimens include: E-glass fibre (artificial fibres) ukam plant, resin, fibres, wax, release agent, gel coat and miscellaneous items. The equipment used are weighing balance, cloth, stirrers, measuring cylinder, universal testing machine.

\subsection{Fibre Treatment}

In this study, chemical resetting was used. The procedure involves $\mathrm{NaOH}$ solution treatment, water washing and drying. Natural fibres are extracted from their parent plant. The ukam, sisal and banana are extracted from the back of their stems, while hemp and coconut are extracted from their fruits. The natural fibres, after being extracted, are washed with water to remove gums. The fibres are then treated with sodium hydroxide solution and rammed. The treated fibre was allowed to dry in the sun for 3 days. After which the fibres are laid in the mold with the resin at the ratio of $30 \%$ to $70 \%$. It was allowed to cure for about 20 days.

\subsection{Laminate Manufacture's Methods}

In this study, samples of laminates were made by using hand lay-up method. The method used in this study was employed due to its simplicity and availability of the items. Details of the procedures taken in the production of laminates via hand lay-up method are elsewhere discussed (Agbo, 2009).

\subsection{Measurement}

\subsubsection{Tensile Test}

The tensile tests were performed using a testing machine model 8889. The width and the thickness of the specimens were measured and recorded (360 mm by $20 \mathrm{~mm}$ by $5 \mathrm{~mm}$ ). The tensile tests were carried out according to ASTM D 038-01. The tensile strengths were calculated from this test.

\subsubsection{Bending Test}

Three point bending tests were performed using a testing machine in accordance to ASTM D 790 standards. For the bending test, samples with dimensions of $300 \mathrm{~mm} \times$ $20 \mathrm{~mm} \times 5 \mathrm{~mm}$ were used. The bending strength test was carried out on the tensometer with its attachment fixed properly bending strengths were evaluated. 


\subsubsection{Izod Impact Test}

The impact strength of notched specimen was determined by using an impact tester according to ASTM D 256-05 standards. In each case three specimens were tested to obtain average value.

\section{Results and Discussion}

The test results are shown and discussed in this section. Average values of three replications of the tensile test, the bending test, the compressive test, and the impact test are tabulated in Table $\mathbf{1}$.

\subsection{Compressive and Tensile Strength}

Figures 1 and 2 show the compressive and tensile strength of the alkalized treatment of ukam, banana, sisal, coconut, hemp and E-glass fibres. From the histograms, it is obvi- ous that sisal laminate displayed the highest (42.0 MPa) compressive strength, followed by ukam laminate, then E-glass laminate, while the banana showed the lowest (16.75 MPa) compressive strength. Figure 2 shows the measured tensile strength of treated natural fibres. The tensile strength decreases from E-glass laminate with highest (63 MPa) tensile strength, ukam laminate (16.25 $\mathrm{MPa}$ ), while hemp laminate showed the least (7.0 MPa) tensile strength. However other parameters that are important are assessed for good suitability.

\subsection{Bending Strength}

Figure 3 shows the bending strength of alkalized natural fibres. E-glass displayed highest (0.50 MPa), next to it is sisal laminate, followed by coconut and hemp, while ukam and banana showed the least (0.0013 MPa) bending strength.

Table 1. Mechanical properties of various composite laminate.

\begin{tabular}{lcccccc}
\hline \multicolumn{1}{c}{$\begin{array}{c}\text { Mechanical } \\
\text { properties }\end{array}$} & $\begin{array}{c}\text { Ukam fibre } \\
\text { Laminate }\end{array}$ & $\begin{array}{c}\text { Banana fibre } \\
\text { laminate }\end{array}$ & $\begin{array}{c}\text { Sisal fibre } \\
\text { Laminate }\end{array}$ & $\begin{array}{c}\text { Coconut fibre } \\
\text { laminate }\end{array}$ & $\begin{array}{c}\text { E-glass } \\
\text { laminate }\end{array}$ & $\begin{array}{c}\text { Hemp fibre } \\
\text { laminate }\end{array}$ \\
\hline Compressive strength (MPa) & 39.25 & 16.75 & 42.00 & 30.35 & 37.75 & 29.75 \\
Tensile strength (MPa) & 16.25 & 6.50 & 5.40 & 3.20 & 63.00 & 7.00 \\
Bending strength (MPa) & 0.0013 & 0.0013 & 0.0036 & 0.0021 & 0.500 & 0.0017 \\
Impact strength $\left(\mathrm{J} / \mathrm{m}^{2}\right)$ & 9.89 & 7.47 & 8.36 & 8.36 & 17.82 & 7.41 \\
\hline
\end{tabular}

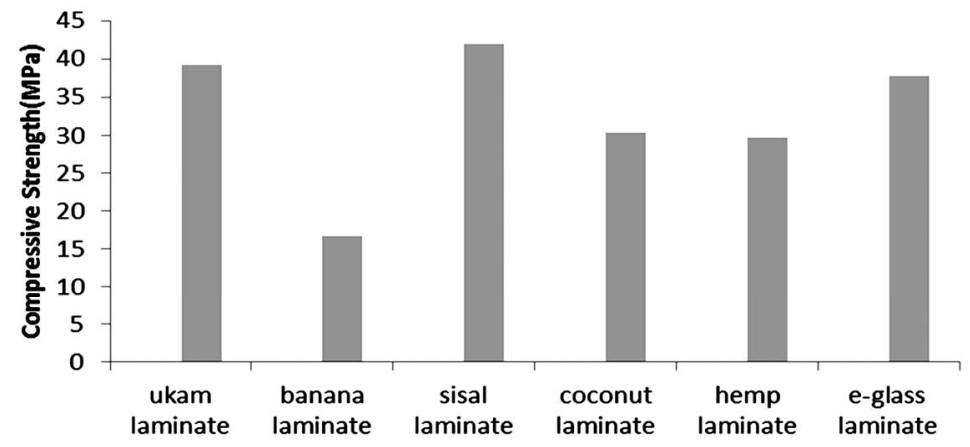

Figure 1. Compressive strength of alkalized treatment of natural fibre reinforced laminate samples.

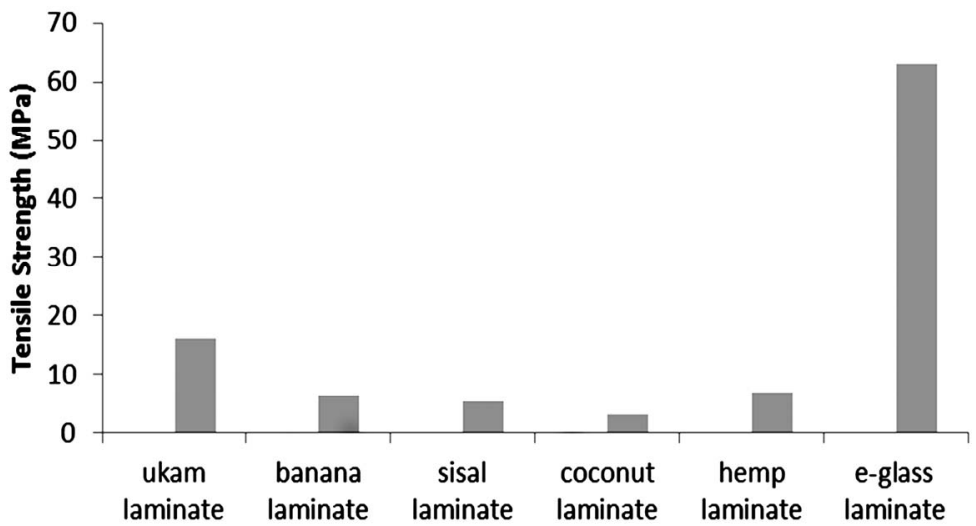

Figure 2. Tensile strength of alkanized treatment of natural fibre reinforced laminate samples. 


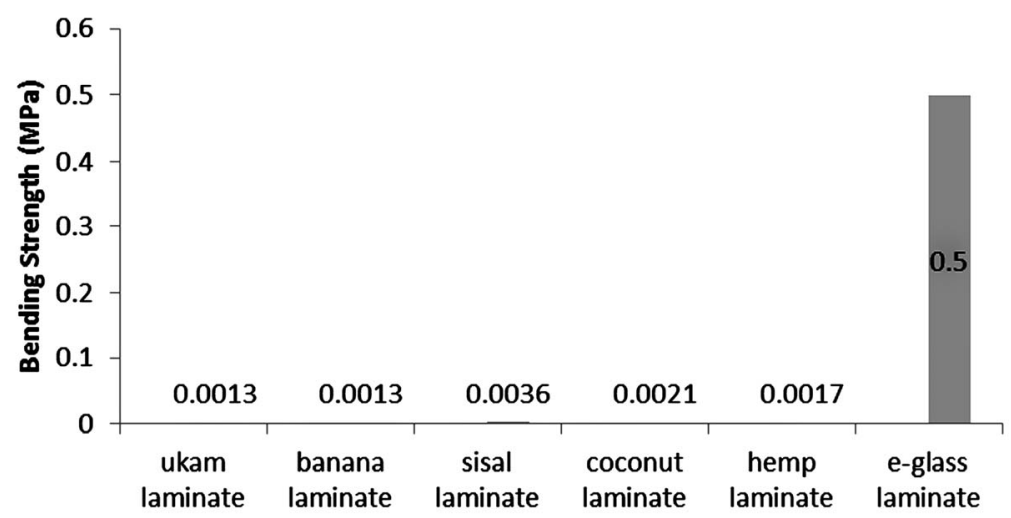

Figure 3. Bending strength of alkanized treatment of natural fibre reinforced laminate samples.

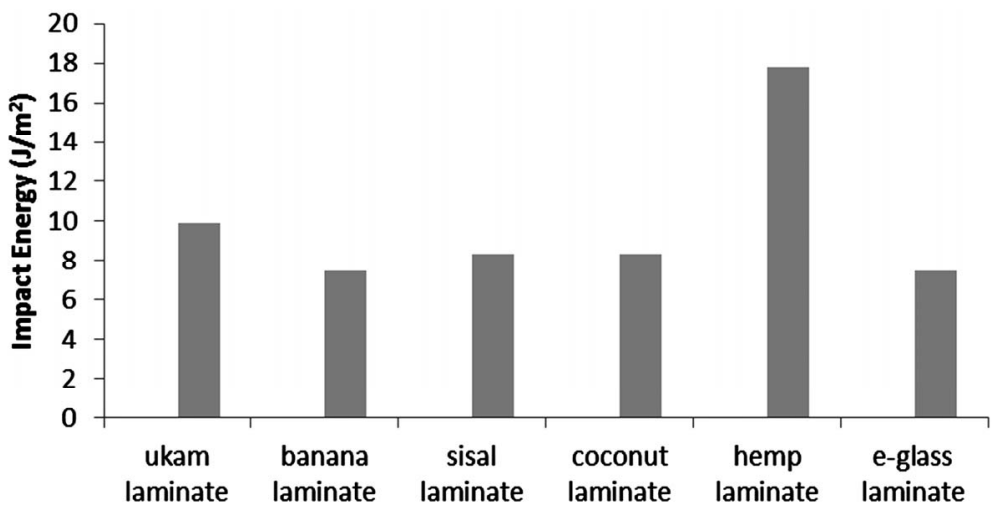

Figure 4. Impact strength of alkanized treatment of natural fibre reinforced laminate samples.

\subsection{Impact Strength}

Figure 4 shows the izod impact strength results of reinforced fibre laminates. The ukam laminate tested displayed higher impact strength $\left(9.87 \mathrm{~J} / \mathrm{m}^{2}\right)$ next to E-glass laminate $\left(17.82 \mathrm{~J} / \mathrm{m}^{2}\right)$, while the hemp and bananana displayed the lowest $\left(7.477 \mathrm{~J} / \mathrm{m}^{2}\right)$.

The alkalization treatment of fibers helps in improving the chemical bonding between the resin and fiber resulting in superior mechanical properties. It has been reported by several authors that mechanical properties of composites were improved by the modification of fibers [20].

\section{Conclusions}

The experimental investigation on mechanical properties of natural fiber reinforced composites leads to the following conclusions:

1) The natural fiber composite manufactured by hand lay-up process provides an opportunity of replacing existing materials with a higher strength, low cost alternative that is environmentally friendly.

2) Mechanical properties viz., Compressive strength, Bending strength, Tensile strength, and Impact strength of the ukam and sisal fiber reinforced composite material is greatly influenced by alkalization treatment. Hence, ukam and sisal fibers can be good reinforcement candidates for high performance polymer composites.

3) Ukam and sisal composites manufactured by hand lay-up process provide an opportunity of replacing existing materials with a higher strength, low cost alternative that is environmentally friendly.

\section{REFERENCES}

[1] R. Karnani, M. Krishnan and R. Narayan, "Biofiber-Reinforced Polypropylene Composites,” Polymer Engineering and Science, Vol. 37, No. 2, 1997, pp. 476-483.

[2] A. M. Mohd Edeerozey, M. A. Harizan, A. B. Azhar and M. I. Zainal Ariffin, "Chemical Modification of Kenaf Fibers,” Materials Letters, Vol. 61, No. 10, 2007, pp. 2023-2025. doi:10.1016/j.matlet.2006.08.006

[3] E. Robson, "Surface Treatment of Natural Fibre," EC/ 4316/92, 1993.

[4] H. A. Sharifah and P. A. Martin, "The Effect of Alkalization and Fibre Alignment on the Mechanical and Thermal Properties of Kenaf and Hemp Bast Fibre Composites: Part 1-Polyester Resin Matrix,” Composites Science and Technology, Vol. 64, No. 9, 2004, pp. 1219-1230.

[5] B. F. Yousif, K. J. Wong and N. S. M. El-Tayeb, "An Investigated on Tensile, Compression and Flexural Prop- 
erties of Natural Fibre Reinforced Polyester Composites,” ASME International Mechanical Engineering Congress and Exposition, Seattle, 11-15 November 2007, pp. 619624.

[6] Y. Mohd Yuhazri, P. T. Phongsakorn and H. Sihambing, “A Comparison Process between Vacuum Infusion and Hand Lay-Up Method toward Kenaf/Polyester Composite,” International Journal of Basic \& Applied Sciences, Vol. 10, No. 3, 2010, pp. 63-66.

[7] T. Nishino, K. Hirao, M. Kotero, K. Nakamae and H. Inagaki, "Kenaf Reinforced Biodegradable Composite," Composites Science and Technology, Vol. 63, No. 9, 2003, pp. 1281-1286. doi:10.1016/S0266-3538(03)00099-X

[8] H. A. Sharifah, P. A. Martin, J. C. Simon and R. P. Simon, "Modified Polyester Resins for Natural Fibre Composites," Composites Science and Technology, Vol. 65, No. 3-4, 2005, pp. 525-535. doi:10.1016/j.compscitech.2004.08.005

[9] P. Wamubua, J. Ivens and I. Verpoest, "Natural Fibres: Can They Replace Glass in Fibre Reinforced Plastics?” Composites Science and Technology, Vol. 63, No. 9, 2003, pp. 1259-1264. doi:10.1016/S0266-3538(03)00096-4

[10] C. Benjamin and Tobias, "Fabrication and Performance of Natural Fiber-Reinforced Composite Material,” 35th International SAMPLE Symposium and Exhibition, Anaheim, 2-5 April 1990, pp. 970-978.

[11] S. Agbo, "Modelling of Mechanical Properties of a Natural and Synthetic Fiber-Reinforced Cashew Nut Shell Resin Composites,” M.Sc. Thesis, University of Nigeria, 2009.

[12] A. Stamboulis and C. Baley, "Effects of Environmental Conditions on Mechanical and Physical Properties of Flax Fibres," Composites Part A: Applied Science and Manufacturing, Vol. 32, No. 8, 2001, pp. 1105-1115.

[13] M. Brahmakumar, C. Pavithran and R. M. Pillai, "Coconut Fibre Reinforced Polyethylene Composites: Effect of Natural Waxy Surface Layer of the Fibre on Fibre/Matrix
Interfacial Bonding and Strength of Composites," Composites Science and Technology, Vol. 65, No. 3-4, 2005, pp. 563-569.

[14] M. Hautala, A. Pasila and J. Pirila, "Use of Hemp and Flax in Composite Manufacture: A Search for New Production Methods," Composite Part A: Applied Science and Manufacturing, Vol. 35, No. 1, 2004, pp. 11-16.

[15] I. O. Oladele, J. A. Omotoyinbo and J. O. T. Adewara, "Investigating the Effect of Chemical Treatment on the Constituents and Tensile Properties of Sisal Fibre,” Journal of Minerals and Materials Characterization and Engineering, Vol. 9, No. 6, 2010, pp. 569-582.

[16] M. Jacob, S. Thomas and K. T. Varughea, "Mechanical Properties of Sisal/Oil Palm Hybrid Fibre Reinforced Natural Rubber," Composites Science and Technology, Vol. 64, No. 7-8, 2004, pp. 955-965. doi:10.1016/S0266-3538(03)00261-6

[17] A. Pelet, S. Sueki and B. Mobasher, "Mechanical Properties of Hybrid Fabrics in Pultruded Cement Composites," 16th European Conference of Fracture, Special Symposium Measuring Monitoring and Modelling Concrete properties Alexandrroupolis, Greece, 2006.

[18] H. P. S. A. Khalil and H. D. Rozman, "Rice-Husk Polyester Composites: The Effect of Chemical Modification of Rice Husk on the Mechanical and Dimensional Stability Properties," Polymer Plastic and Technology Engineering, No. 39, 2007, pp. 757-781.

[19] S. Shibata, Y. Cao and I. Fukumoto, "Press Forming of Short Natural Fiber-Reinforced Biodegradable Resin: Effects of Fiber Volume and Length on Flexural Properties," Polymer Testing, Vol. 24, No. 8, 2005, pp. 10051011. doi:10.1016/j.polymertesting.2005.07.012

[20] M. Idricula, S. K. Malhota, K. Joseph and S. Thomas, "Dynamic Mechanical Analysis of Randomly Oriented Intimately Mixed Short Banana/Sisal Hybrid Fibre Reinforced Polyesters Composites," Composites Science and Technology, Vol. 65, No. 7-8, 2005, pp. 1077-1087. doi:10.1016/j.compscitech.2004.10.023 